\title{
Erratum to: Nitrogen Heterosubstitution in Graphene Nanoflakes: An Effective Approach to Improving Performance of Supercapacitors with Ionic Liquid Electrolyte
}

\author{
E. A. Arkhipova ${ }^{a, *}$, A. S. Ivanov ${ }^{a}$, K. I. Maslakov ${ }^{a}$, S. A. Chernyak ${ }^{a}$, and S. V. Savilov ${ }^{a, b}$ \\ ${ }^{a}$ Department of Chemistry, Lomonosov Moscow State University, Moscow, 119991 Russia \\ ${ }^{b}$ Kurnakov Institute of General and Inorganic Chemistry, Russian Academy of Sciences, Moscow, 119991 Russia \\ *e-mail: ekaterina.a.arkhipova@gmail.com
}

Received June 16, 2021; revised June 16, 2021; accepted June 16, 2021

DOI: $10.1134 / \mathrm{S} 0036024421310022$

The article "Nitrogen Heterosubstitution in Graphene Nanoflakes: An Effective Approach to Improving Performance of Supercapacitors with Ionic Liquid Electrolyte," written by E. A. Arkhipova, A. S. Ivanov, K. I. Maslakov, S. A. Chernyak, and S. V. Savilov, was originally published electronically in Springer-Link on 5 April 2021 without Open Access. After publication in volume 95, issue 3, pages 565-569 the authors decided to make the article an Open Access publication. Therefore, the copyright of the article has been changed to (C) The Author(s), 2021 and the article is forthwith distributed under the terms of a Creative Commons Attribution 4.0 International License (http://creativecommons.org/licenses/by/4.0/, CC BY), which permits use, duplication, adaptation, distribution and reproduction of a work in any medium or format, as long as you cite the original author(s) and publication source, provide a link to the Creative Commons license, and indicate if changes were made.

The original article can be found online at https://doi.org/10.1134/S0036024421030031 